\title{
BANKING COMPETITION AND WELFARE
}

\author{
Marcella Lucchetta \\ University of Venice, Dept. of Economics
}

October, 2016

\begin{abstract}
We develop a simple general equilibrium model in which investment in a risky technology is subject to moral hazard and banks can extract market power rents. We show that more bank competition results in lower economy-wide risk, higher social welfare, lower bank capital ratios, more efficient production plans and Pareto-ranked real allocations. Perfect competition supports a second best allocation and optimal levels of bank risk and capitalization. These results are at variance with those obtained by a large literature that has studied a similar environment in partial equilibrium, they are empirically relevant, and carry significant implications for policy guidance.
\end{abstract}




\section{INTRODUCTION}

The existence of a trade-off between competition and bank risk-taking, and by extension, between competition and financial stability, is rooted in a special version of an intuitively appealing and powerful argument, the "charter value hypothesis" (CVH). The CVH states that under limited liability and unobservable risk choices, a borrower will choose riskier investments when the cost of debt is higher, since she will fully enjoy the upside of its return if the investment outcome is favorable, but its losses will be limited in the case of an adverse investment outcome. Thus, higher funding costs due to increased competition will erode a borrower's charter value (expected profits), prompting her to take on more risk.

However, as shown in Berger et al. (2009) and Zigraiova and Havranek (2015), theory and empirics about the relation between bank competition and financial stability offer contrasting results. A recent work of Akins et al. (2016) find empirically that banks facing less competition are more likely to engage in risky activities. Importantly, welfare implications and the optimal level of banking capital are not clearly assessed, despite the importance of the topic ${ }^{1}$. We provide a clear and simple model that allows the answer to these important research questions.

The $\mathrm{CVH}$ has been implemented by modeling banks as entities raising funds from insured depositors and choosing the risk of their investment portfolio. If deposits become more expensive due to increased competition for funding, then there is an incentive for banks to take on more risk. This implication has been illustrated by Allen and Gale (2000 and

\footnotetext{
${ }^{1}$ Freixas and $\mathrm{Ma}$ (2015) show that competition affects the level of risk depending on banks' leverage, where they assume the cost of capital higher than the cost of debt. Regarding the welfare dimension, Maudos and de Guevara (2007) show empirically that the welfare gains associated with a reduction of market power in the banking sector are greater than the loss of bank cost efficiency.
} 
2004a) in both static and simple dynamic settings, and it is the key thrust of work by Keeley (1990), Matutes and Vives (1996), Hellmann, Murdock and Stiglitz (2000), Cordella and Levi-Yeyati (2002), Repullo (2004), and many others. Importantly, the CVH is also a key ingredient of many models that rationalize the incentives for banks to take on more risk under deposit insurance, as well as a basic tenet underlying key bank regulations, such as capital requirements. ${ }^{2}$

However, when banks compete in both loan and deposit markets, Boyd and De Nicolò (2005) showed that the trade-off between competition and financial stability can vanish. In their model, firms choose the risk of their investment given the loan rates charged by banks, while banks provide loans to firms with insured deposits. Thus, risk is determined jointly by firms and banks. An increase in bank competition reduces loan rates charged to firms, but increases the cost of funds for banks. As firms' charter value increases with lower loan rates, they choose safer investments, which in turn translates into a safer loan portfolio for banks. The charter value of the bank is reduced by the increase in the deposit rates, but under an assumption of perfect diversification, the equilibrium outcome is one in which banks find it optimal to choose lower loan rates as competition increases. Thus, in this more complex setting the $\mathrm{CVH}$ is applied to two entities—-firms and banks - and their charter values are interlinked. Recent extensions of this type of model—introducing different assets (Boyd, De Nicolò and Jalal, 2006 and 2009), bank heterogeneity (De Nicolò and Loukoianova, 2007), or a different risk structure (Martinez-Miera and Repullo, 2010 and Freixas and Ma, 2015) — have all essentially aimed at establishing under what conditions the trade-off between competition and financial stability predicted by the CVH holds.

\footnotetext{
${ }^{2}$ For detailed surveys of these literatures, see Gorton and Winton (2003) and Freixas and Rochet (2008).
} 
As pointed out by Allen and Gale (2004a), however, the trade-off between competition and financial stability identified by a large portion of the literature is based on partial equilibrium modeling. In their general equilibrium formulation of a Diamond and Dybvig (1983)-type economy, Allen and Gale (2004b) demonstrate that perfect competition among intermediaries is Pareto optimal under complete markets, and constrained Pareto optimal under incomplete markets, with financial "instability" as a necessary condition of optimality. Analogous results are obtained under low inflation in the general equilibrium monetary economy with aggregate liquidity risk analyzed by Boyd, De Nicolò and Smith (2004). ${ }^{3}$ Although these general equilibrium results utterly contrasts with the conventional wisdom based on many partial equilibrium formulations of the $\mathrm{CVH}$, a direct comparison between these formulations is not entirely appropriate, as these general equilibrium models do not feature the type of moral hazard in investment associated with financing choices on which the CVH is based.

In this paper we assess the general equilibrium implications of the $\mathrm{CVH}$ for competition, financial stability and welfare in two versions of a simple general equilibrium model in which the choice of the risky investment is unobservable by investors: this is precisely the type of information asymmetry generating the moral hazard problem highlighted in partial equilibrium formulations of the $\mathrm{CVH}$. Our analysis is not only of theoretical interest, as the $\mathrm{CVH}$ has had, and still has a great influence in informing financial policy

\footnotetext{
${ }^{3}$ Boyd, Chang and Smith (2002) also show that some of the standard implications of partial equilibrium modeling concerning the risk effects of deposit insurance may not necessarily hold in general equilibrium.
} 
In our set-up, agents specialize in production at the start date, choosing to become either firm-entrepreneurs, or bank-entrepreneurs, or depositors, and at a later date they make their investment and financing decisions. We establish a mapping between bank market power rents and investment and consumption allocations independently of any specific assumption on the mechanism generating a given level of bank market power rents following three steps. Specifically, we first identify equilibriums with intermediation parameterized by a given interest rate on debt contracts. Second, we characterize first best and constrained optimality, and define a perfectly competitive equilibrium as the interest rate that supports a core allocation. Lastly, bank market power rents are defined as the deviation of an equilibrium interest rate from the interest rate prevailing at a core (perfectly competitive) allocation.

We consider two versions of the model. The first version has banks as coalitions of entrepreneurs that are financed by depositors. In the second version, the first model is extended to include firms financed by banks funded with deposits. In both models, we show that lower banks' market power rents result in lower economy-wide risk, lower capital ratios, more efficient production plans and Pareto-ranked real allocations. Perfect competition, in the form of the absence of banks' market power rents, supports a (second) best allocations and optimal levels of bank risk and capitalization. Thus, a general equilibrium economy with investment choices subject to moral hazard delivers implications identical to those obtained by Allen and Gale (2004b) and Boyd, De Nicolò and Smith (2004) in economies lacking these features.

It is remarkable that in general equilibrium the implications of the $\mathrm{CVH}$ for bank risk and bank capitalization turn out to be exactly opposite to what a partial equilibrium set-up 
would imply. This is because the partial equilibrium interpretation of the $\mathrm{CVH}$ remains a good description of incentives, but it is not necessarily a good predictor of actual outcomes.

The key reasons why the CVH produces different outcomes in partial as opposed to general equilibrium are as follows. In partial equilibrium, the $\mathrm{CVH}$ is based on treating the amount of available funding for a bank or a firm as either given, or represented by supply and demand functions that are determined independently. Likewise, agents' choices of whether specializing in production, intermediation or becoming depositors are typically either treated as exogenous or assumed to be independent. Therefore, an increase in the cost of funding prompts either banks, or firms financed by banks, to choose riskier investment for any given amount of funding they obtain. By contrast, in general equilibrium agents' specialization choices as well as their funding decisions are not independent. Thus, an increase in the cost of funding will also increase the amount of funding available for investment. In our set-up, such an increase will offset the negative impact of higher funding costs on borrowers' charter values. Thus, the equilibrium outcome of an increase in the cost of funding results in borrowers choosing a lower rather than a higher level of risk.

Importantly, an increasing number of studies support the empirical relevance of our theoretical results. Recent detailed studies on the effects of a variety of barriers of entry impeding competition, as well as of capture of borrowers, supports the implications of our model. For example, Jayaratne and Strahan (1998) find that branch deregulation resulted in a sharp decrease in loan losses. Restrictions on banks' entry and activity have been found to be negatively associated with some measures of bank stability by Barth, Caprio and Levine (2004) and Beck (2006a and 2006b). Furthermore, work that links bank competition to economic growth is supportive of the positive role of bank competition on growth. For 
example, Cetorelli and Gambera (2001) and Cetorelli and Strahan (2006) find that banks with market power erect an important financial barrier to entry to the detriment of the entrepreneurial sector of the economy, leading to long-term declines in a country's growth prospect. Lastly, De Nicolò and Loukoianova (2009), Boyd, De Nicoló and Jalal (2006, 2009), Boyd, De Nicolò and Loukoianova (2009), and De Nicolò and Turk Ariss (2009), find that a variety of measures of bank risk, as well as bank systemic risk, indicate a positive association between financial stability and stronger bank competition.

The remainder of the paper is composed of five sections. Section II describes the basic version of the model with banks and depositors only. Section III proves existence of equilibriums under moral hazard and, for comparison, a no-moral hazard version for given interest rates on debt contracts, illustrating the relevant comparative statics. Section IV characterizes optimality, defines bank market power rents, and establishes the inverse relationship between bank market power rents and optimality. Section $V$ consider the extended version of the model with firms, banks and depositors, and demonstrates that all results obtained in the basic version of the model continue to hold in the extended model. Section VI concludes. Proofs of all propositions are in the Appendix.

\section{THE BaSIC ModeL}

\section{A. Time, Endowments and Preferences}

There are three dates, 0,1 and 2 , and a continuum of agents on $[0,1]$ indexed by $q \in[0,1]$. A type- $q$ agent has an endowment of $q W$ units of date 0 good and labor $\bar{l}$. Total date 0 goods in the economy are therefore $W \int_{0}^{1} q d q=\frac{W}{2}$, with $W>1$. 
The type of an agent is the agent's private information. We assume it cannot be observed by any other agent, or communicated credibly to any other agent at any feasible resource cost. In practice, this assumption of unobservability of types is similar to the unobservability of projects' types in the model by Boyd and Prescott (1986). As in that model, it rules out the possibility that contracting among agents at the initial date is made conditional on their endowments.

All agents have preferences over date 2 consumption only, are risk neutral, and derive disutility from work. Accordingly, preferences are represented by $U(c)-V(l)$, where $U(c)=c$ and $V(l)=\frac{\alpha}{2} l^{2}$

\section{B. Technologies}

All agents have a costly access to an "entrepreneurial" technology that requires investment of all their date 0 good endowment, and allows them to undertake a risky project at date 1. If an agent chooses to operate a risky project, then he/she becomes an entrepreneur. Otherwise, an agent becomes an investor and her endowment of date 0 good is carried over to date 1 .

Agents differ with respect to the resource cost incurred in becoming entrepreneurs. Specifically, the "entrepreneurial" technology allows an agent $q \in[0,1]$ to choose and operate a risky technology at date 1 by transforming all his date 0 good endowment into an amount $k \in(0, W)$ of date 1 goods. Thus, the resource cost for agent $q$ to become an entrepreneur is $q W$, and the opportunity cost of becoming entrepreneurs increases with agents' endowments of date 0 good. Equivalently, agents with a smaller endowment have a more "productive" entrepreneurial technology. 
We interpret the level of $k$ as the capital available to a bank-entrepreneur. As we show below, aggregate capital will be determined endogenously in equilibrium. This feature of our model is novel relative to the set-ups by Holmstrom and Tirole (1997) and Boot and Thakor (1997), where the aggregate levels of internal funding by either firms or intermediaries are exogenously given.

Becoming an entrepreneur entails access to a set of risky projects with constant returns to scale. Projects are indexed by their probability of success $p \in[0,1]$. A $p$-project yields $X$ per unit invested with probability $p$, and 0 otherwise.

In the basic version of the model, project outcomes are assumed to be perfectly correlated. As noted in Allen and Gale (2000), this assumption is equivalent to assuming that the risk of each investment can be decomposed into a common and an idiosyncratic component, and that the idiosyncratic component can be diversified away with a large number of investments.

Choosing $p$ requires labor, according to the linear technology $p=l$. Thus, an

entrepreneur will incur a disutility $V(p)=\frac{\alpha}{2} p^{2}$ in choosing a $p$-project.

As noted, as an alternative to becoming an entrepreneur, an agent can become an investor, who lends his/her endowment at date 1 to a set of entrepreneurs, as detailed below.

\section{Contracts and information}

Once agents have decided whether to become entrepreneurs or investors, they pool resources to finance investment at date 1 . We call these coalitions of entrepreneurs and investors "banks". Since the production technology is constant return to scale, the size 
distribution of banks is indeterminate ${ }^{4}$. For this reason, it is noteworthy that any result we obtain below is independent of market structure.

We assume that investors, called depositors, finance banks with simple debt contracts. These contracts pay a fixed amount $\hat{R}$ per unit invested if the investment outcome is successful, and 0 otherwise.

We do not place any specific restrictions on agents' interactions, assuming just that banks and depositors will bargain over $\hat{R}$ at date 1 . A lower $\hat{R}$ will be viewed as associated with a stronger bargaining power of banks vis a vis depositors. Thus, as made precise below, we associate a lower level of $\hat{R}$ with a higher level of rent extraction by banks, and treat $\hat{R}$ as an exogenous parameter indexing the level of bank market power rents.

We should stress that our focus is on the effects of banks' market power rents on risk and real allocations. Thus, we refrain to model any specific bargaining game generating certain levels of rents. For our purposes, the existence of rents suffices, whatever is the mechanism that generates them.

We consider equilibrium outcomes under two information structures. In the moral hazard case, we assume that the choice of $p$ is privately observed by banks, so that there is moral hazard. Thus, banks and depositors will bargain over a given value of $\hat{R}=R$, independent of the (unobservable) choice of risk $p$. In the no-moral hazard case the choice of $p$ is publicly observed by both banks and depositors, so that there is no moral hazard.

\footnotetext{
${ }^{4}$ See Krasa and Villamil (1992) for a model of a bank with imperfect diversification and an optimal bank size.
} 
Therefore, banks and depositors will bargain over a given value of $\hat{R}=\frac{R}{p}$, which does depend on the (observable) choice of risk $p$.

The sequence of events in this economy is summarized as follows. At date 0 , agents decide to become banks or depositors. At date 1, banks and depositors bargain on $R$, and once an agreement is reached, bankers choose $p$ and investment occurs. At date 2, the output is realized, and consumption follows.

\section{EQUILIBRIUM WITH BANKS AND DEPOSITORS}

In this section we establish existence of unique equilibriums for given values of $\hat{R}$, and characterize the comparative statics of the model with respect to changes in $\hat{R}$ under moral hazard, and for comparison, under no-moral hazard as well.

\section{A. Moral Hazard}

Let $I$ denote depositors' total supply of funds. Given $I$, at date 1 any coalition of bank-entrepreneurs of positive measure $\lambda>0$ will choose $p$ to maximize

$$
\left(p[(X-R) I+X k]-\frac{\alpha p^{2}}{2}\right) \lambda
$$

We focus on interior solutions, denoted with *. The optimal choice of $p$ satisfies

$$
p^{*}=\frac{(X-R) I+X k}{\alpha}
$$

In partial equilibrium, problem (1) represents a simple formulation of the incentives induced by the CVH. Its solution (2) represents the relevant outcome. Given I, an increase in 
$R$ will decrease banks' profits in the good state, prompting them to increase risk by choosing a lower $p$. However, in general equilibrium depositors' supply of funds $I$ is not given, but determined endogenously. If $I$ increases with $R$, and this increase offsets the decline in bank profits due to an increase in $R$, then in equilibrium $p$ will increase. The general equilibrium outcome of the CVH may turn out to be exactly of the opposite sign of its partial equilibrium counterpart. Indeed, we demonstrate this to be the case next.

The profits per bank-entrepreneur in a coalition are:

$$
\Pi(I) \equiv p^{*}[(X-R) I+X k]-\frac{\alpha p^{2}}{2}=\frac{[(X-R) I+X k]^{2}}{2 \alpha}
$$

Therefore, at date 0 an agent $q \in[0,1]$ will choose to become a bank-entrepreneur if

$$
\Pi(I) \geq p^{*} R q W
$$

Let $\hat{q}$ denote the agent who is indifferent between being a bank-entrepreneur or an investor. Then,

$$
\Pi(I)=p^{*} R \hat{q} W
$$

Clearly, all agents with $q \in[0, \hat{q}]$ will become bank-entrepreneurs, while those with $q \in(\hat{q}, 1]$ will become depositors. Therefore, the fractions of bank-entrepreneurs and depositors are $\hat{q}$ and $1-\hat{q}$ respectively.

Note that for any bank to attract external funding, $R \in(0, X]$. Of course, no agent would become a depositor if $R=0$, while no bank would raise any funding from depositors if $R>X$. 
Absent intermediation, in this economy all agents would become entrepreneurs and invest their funds in risky projects, but this autarkic arrangement would be clearly highly inefficient. Thus, intermediation can be viewed as essential in a weak sense: as intermediation arrangements improve on agents' welfare under autarky, then they will likely be set up. However, other decentralized arrangements, such as credit markets, might attain the same allocations, and could be adopted as well, exclusively or in combination.

We focus on equilibriums with intermediation, defined as follows:

Definition. An equilibrium with intermediation is a triplet $\left(I^{*}, p^{*}, \hat{q}^{*}\right)$ and a value $R \in\left\{\hat{R} \in(0, X]: I^{*} \geq 0, p^{*} \in(0,1), q^{*} \in(0,1)\right\}$ such that:

$$
\begin{array}{r}
p^{*}=\frac{(X-R) I^{*}+X k}{\alpha} \\
\Pi\left(I^{*}\right)=p^{*} R \hat{q}^{*} W \\
I^{*}=W \int_{\hat{q}^{*}}^{1} q d q=\frac{W\left(1-\hat{q}^{2}\right)}{2}
\end{array}
$$

Thus, an equilibrium triplet $(I, p, q)$ satisfies the following conditions:

$$
\begin{aligned}
& p=\frac{(X-R) I+X k}{\alpha} \\
& \frac{[(X-R) I+X k]}{2}=R q W \\
& I=\frac{W\left(1-q^{2}\right)}{2}
\end{aligned}
$$

The existence of equilibriums with intermediation is proved in the following 
Proposition 1. In the moral hazard economy with banks and depositors an

equilibrium with intermediation exists and it is unique for every $R \in\left(\frac{X k}{2 W}, X\right]$.

Denote with $Y_{z} \equiv \frac{d Y}{d z}$ the change in the endogenous variable $Y$ with respect to parameter $z$. In this economy, the endogenous aggregate bank capital ratio is given by $K=\frac{q k}{I+q k}$.

The comparative statics of the equilibrium triplet $\left(I^{*}, p^{*}, \hat{q}^{*}\right)$ and $K^{*}$ with respect to $R$, as well as that of $p^{*}$ with respect to $k$, is summarized in the following.

Proposition 2. In the moral hazard economy with banks and depositors:

$$
I_{R}^{*}>0, \hat{q}_{R}^{*}<0, p_{R}^{*}>0, K_{R}^{*}<0 \text { and } p_{k}^{*}>0 .
$$

Proposition 2 illustrates how the general equilibrium outcome of the $\mathrm{CVH}$ turns out to be opposite to its partial equilibrium counterpart. As $R$ increases, bank profits decline, ceteris paribus. This will induce a larger fraction of agents to become depositors, and correspondingly a smaller fraction of agents to become bank-entrepreneurs. As a result, the total amount of funds available to banks will increase. Bank profits will on net increase, since the increase in $I$ offsets the decline in profits due to a higher cost of funds $R$. Therefore, banks will choose safer risky projects, corresponding to a higher $p$.

Proposition 2 also illustrates the equilibrium relationship between bank capitalization and risk. As $R$ increases, the capital ratio of the banking system declines, but this decline does 
not necessarily imply that bank risk has increased, since $p$ goes up. Thus, the association typically made in partial equilibrium between higher capital ratios and lower bank risk does not necessarily hold in general equilibrium. However, ceteris paribus, a larger availability of per-bank capital induces banks to take on less risk, since $p$ increases with $k$.

\section{B. No Moral Hazard}

It is useful to compare the foregoing results with the outcomes of an economy where there is no moral hazard. To this end, here we assume that the choice of $p$ is observable. As

noted previously, the debt contract now pays $\frac{R}{p}$ per unit invested, as investors take fully into account the observable risk they are exposed to in their specialization and investment decisions.

At date 1 , any coalition of bank-entrepreneurs of any positive measure $\lambda>0$ will choose $p$ to maximize

$$
\left(p X(I+k)-R I-\frac{\alpha p^{2}}{2}\right) \lambda
$$

The interior solution is:

$$
p^{*}=\frac{X(I+k)}{\alpha}
$$

Absent moral hazard, by (12) the choice of risk does not depend anymore directly on $R$ : therefore, bank's risk shifting does not occur.

The profits per bank-entrepreneur in any coalition of positive measure are:

$$
\Pi(I) \equiv p^{*} X(I+k)-R I-\frac{\alpha p^{2}}{2}=\frac{X^{2}(I+k)^{2}}{2 \alpha}-R I
$$


Let $\hat{q}$ denote the agent who is indifferent between being a bank-entrepreneur or a depositor. Then,

$$
\Pi(I)=R \hat{q} W
$$

To sum up, an equilibrium is a triplet $(I, p, q)$ that satisfies the following conditions:

$$
\begin{gathered}
p=\frac{X(I+k)}{\alpha} \\
\frac{X^{2}(I+k)^{2}}{2 \alpha}-R I=R q W \\
I=\frac{W\left(1-q^{2}\right)}{2}
\end{gathered}
$$

In this case, the existence of equilibriums with intermediation is proved in the following

Proposition 3. , In the no-moral hazard economy with banks and depositors an equilibrium with intermediation exists and it is unique for every $R \in\left(\frac{X^{2} k^{2}}{2 \alpha W}, \frac{X^{2}(W+2 k)^{2}}{4 \alpha W}\right)$.

The comparative statics of the equilibrium triplet $\left(I^{*}, p^{*}, \hat{q}^{*}\right)$ with respect to $R$ and $k$ is summarized in:

Proposition 4. In the no-moral hazard economy with banks and depositors:

$$
I_{R}^{*}>0, \hat{q}_{R}^{*}<0, p_{R}^{*}>0, K_{R}^{*}<0 \text { and } p_{k}^{*}>0 \text {. }
$$

It is apparent that the comparative statics with no-moral hazard is identical to that with moral hazard. This equivalence suggests that the negative relationship between bank risk-taking and the cost of funds $R$ is robust to the presence or the absence of the CVH. Of 
course, the levels of depositors' supply of funds, bank capitalization, bank risk and real allocations will be different in the no-moral hazard and moral hazard economies.

In the next section, we conduct a welfare comparison of the moral hazard and nomoral hazard economies, and define banks' market power rents precisely.

\section{OPTIMALITY AND INTERMEDIARY RENTS}

Under full observability of types and actions, the set of Pareto optimal (first best)

allocations is defined as the consumption of the representative entrepreneur, $C^{E}$, the consumption allocations of investors, $C^{I}(q)$, an investment allocation decision $I$, and a threshold value of $q$ which solve:

$$
\operatorname{Max} V \equiv q\left(C^{E}-\frac{\alpha}{2} p^{2}\right)+\int_{q}^{1} C^{I}(q) d q
$$

subject to the resource constraints:

$$
\begin{gathered}
q C^{E}+\int_{q}^{1} C^{I}(q) d q=p X(I+k) q \\
I+k q+W \int_{0}^{q} q d q=\frac{W}{2}
\end{gathered}
$$

Substituting (20) in (19), and (19) in (18), planning problem (18) is equivalent to the choice of the threshold $q$ and $p$ to maximize total consumption (equal total output) net of entrepreneurs' disutility of labor:

$$
V(p, q) \equiv p X\left(\frac{W}{2}\left(1-q^{2}\right)+k\right) q-\frac{\alpha p^{2}}{2} q
$$


The objective (21) is strictly concave in both $q$ and $p$. Thus, an interior solution to (21) is unique and characterized by the following first order conditions with respect to $p$ and $q$ :

$$
\begin{aligned}
& X\left(\frac{W}{2}\left(1-q^{2}\right)+k\right) q-\alpha p q=0 \\
& p X\left(\frac{W}{2}\left(1-3 q^{2}\right)+k\right)-\frac{\alpha p^{2}}{2}=0
\end{aligned}
$$

Using (22) and (23) to solve for $p$ and $q$, one obtains:

$$
p^{o}=\frac{2 X(2 k+W)}{5 \alpha} \text { and } q^{o}=\sqrt{\frac{2 k+W}{5 W}}
$$

The solution to the planning problem yields the optimal level of risk $p^{o}$ as well as the optimal degree of specialization $q^{O}$ among agents. ${ }^{5}$ We wish to assess whether there exists any equilibrium indexed by $R$ that attains the optimum in both the moral hazard and nomoral hazard economies. To this end, let $V^{*}=V\left(p^{o}, q^{O}\right)$ denote the value of the welfare criterion at the optimum. Note that any level of $V$ lower than the optimum will result in a Pareto-inferior allocation, since by reallocating productive resources (changing either $q, p$ or both), more output can be produced to give more consumption to some agent without worsening the utility of anybody else. In other words, in this economy a necessary condition

\footnotetext{
5 The rationale behind changes in the optimal values of risk and specialization to changes in parameters are straightforward: The optimal level of risk declines ( $p^{O}$ increases) in both $W$ and $k$, as well as in $X$, and increases in the (utility) cost of choosing $p$-projects, parameterized by $\alpha$. The optimal fraction of entrepreneurs increases in $k$ and declines in $W$.
} 
for any consumption allocation to be Pareto optimal is production efficiency net of disutility of entrepreneurs' labor.

Let $(\hat{p}(R), \hat{q}(R))$ denote the unique equilibrium pair associated with a given $R$. Assessing whether an equilibrium can be optimal amounts to verifying whether there exist a value of $R$ such that $(\hat{p}(R), \hat{q}(R))=\left(p^{O}, q^{O}\right)$.

Under the maintained assumption that intermediation occurs through debt contracts, it is straightforward to show that the Pareto optimal (first best) allocation cannot be achieved in the moral hazard economy:

Proposition 5. In the moral hazard economy with banks and depositors, there is no equilibrium with intermediation that supports the Pareto optimal allocation.

However, a second best allocation is attained by the value of $R$ that maximizes:

$$
\begin{gathered}
V(R) \equiv V(\hat{p}(R), \hat{q}(R)) \\
\text { subject to } R \in\left[\frac{X k}{2 W}, X\right]
\end{gathered}
$$

Denote with $R^{*}$ a solution to problem (25) subject to (26). The following proposition shows that $R^{*}$ is an equilibrium in the moral hazard economy, thus supporting the second best allocation:

Proposition 6. In the moral hazard economy with banks and depositors, $R^{*}$ is an equilibrium with intermediation that supports the second best allocation. 
Perhaps not surprisingly, absent moral hazard, the first best allocation can be achieved, as shown in the following

Proposition 7. In the no-moral hazard economy with banks and depositors, there exist a unique $R^{0}$ such that the corresponding equilibrium with intermediation supports the (first best) Pareto optimal allocation.

In sum, we have established that there exist unique equilibriums in both the moral hazard and no-moral hazard economies such that a best allocation is attained. This identification allows us to define perfect competition among intermediaries and their market power rents, to which we now turn.

Recall that we did not place any restriction on the capability of bank-entrepreneurs and depositors to bargain over debt contract terms and freely form any type of coalition at the initial date. Thus, if coalition formation, setting contract terms, and agents' specialization choice are unfettered, then any bank coalition that offers contract terms that Pareto-improve the allocations of its members relative to any proposal of a competing coalition will block the formation of such competing coalition.

Therefore, as in Boyd and Prescott (1986), we identify perfect competition among banks with an equilibrium in which bank coalitions offer contract terms supporting allocations in the core of this economy. As shown above, this outcome is characterized by bank coalitions offering $R^{*}$ in the moral hazard economy, and $R^{0}$ in the no-moral hazard economy. 
A definition of banks' market power rents follows naturally from the identification of the perfectly competitive outcome as one characterized by the absence of market power rents. Specifically, market power rents are given by the difference between the perfect competitive outcome - indexed by $R^{*}$ in the moral hazard economy, and $R^{0}$ in the no-moral hazard economy — and an equilibrium value of $R$ strictly lower than the corresponding perfectly competitive outcome. We denote market power rents by $\rho .^{6}$

We have also shown that the objective of the planning problem in both economies is a strictly concave function of $R$. Thus all outcomes with $\rho>0$ are Pareto-ranked, in the sense that if $\rho_{1}>\rho_{2}>0$, the allocations associated with $\rho_{2}$ Pareto-improves on the allocations associated with $\rho_{1}$.

Thus, lower market power rents result in lower economy-wide risk, lower bank capitalization, more efficient production plans and Pareto-ranked real allocations, and perfect competition supports a best allocation and optimal levels of risk and bank capitalization: this is our main result, summarized in the following:

Proposition 8 In both the moral-hazard and no-moral hazard economies with banks and depositors, the equilibrium level of risk $\hat{p}$ converges to the optimal level of risk $p^{*}$ from below, to the optimal level of bank capitalization $K^{*}$ from above, and to a best allocation as market power rents vanish, i.e. $\hat{p} \uparrow p^{*}$, and $\hat{K} \downarrow K^{*}$ as $\rho \rightarrow 0$.

\footnotetext{
${ }^{6}$ In our context, we do not view the case $R>R^{*}$ as economically relevant, since the existence of coalitions of depositors extracting market power rents from banks is unrealistic.
} 


\section{EQUILIBRIUM WITH FIRMS, INTERMEDIARIES AND DEPOSITORS}

So far, we have modeled an intermediary as a coalition of entrepreneurs and depositors. This intermediary is germane to the bank as a risk taking agent financed by depositors modeled by many contributions of the literature.

In this section we extend our model so as to include firms distinct from banks. We show that in this extension, all results obtained previously continue to hold. Moreover, in the extended model intermediation has an essential role in allowing the economy not only to reap the benefits of efficient specialization in production, but also those associated with diversification. Thus, intermediation can be viewed as essential in a strong sense: intermediation arrangements improve on agents' welfare under autarky and other decentralized arrangements, such as credit markets, may not attain the same allocations, as in Boyd and Prescott (1986).

\section{A. The Extended Model}

As before, the "entrepreneurial" technology requires to transform all agents" endowment of date 0 good into an amount $k \in(0, W)$ of date 1 goods. Differing from the previous set-up, however, once an agent $q \in[0,1]$ has become an entrepreneur, she can either choose to operate a risky technology at date 1, becoming a firm, or choose to use an “intermediation” technology, becoming a bank.

A firm has access to a set of risky projects indexed by their probability of success $p \in[0,1]$. As before, a $p$-project yields $X$ per unit invested with probability $p$, and 0 otherwise, with the choice of $p$ being privately observed by firms. But again, differing 
from the basic set-up, we assume that the outcome of the project can be observed only at a monitoring cost by outsiders.

Hence, the intermediation technology allows an entrepreneur-in alternative to undertake production directly — to become a monitoring agent by observing the outcome of one project and intermediate funds, that is, to become a bank. The resource cost of doing so is the entire amount $k \in(0, W)$ of date 1 goods. For simplicity every firm is thus paired with a bank-entrepreneur.

At date 1, banks raise funds from depositors, promising $R^{D}$ per unit invested if the bank is solvent. At the same time, they offer funds to firms at the rate $R^{L}$ per unit invested if the firm is solvent.

On the funding side, banks and depositors will bargain over $R^{D}$. On the lending side, $R^{L}$ will be determined by the choice of entrepreneurs to become either firms or banks. Note that depositors are assumed to observe the rate offered by banks to firms at date 1 , and will observe the relevant payments at date 2. Thus, depositors observe banks' actions and their relevant outcomes, but not firms' actions and outcomes directly.

In this modified set-up, intermediation is essential in two key respects. First, it allows firms' projects to be financed, since it makes it feasible for firms to write debt contracts with intermediaries, which in turn can raise finance through the same contracts from depositors. Second, under the assumption that project realizations are independent, intermediaries are instrumental in allowing the economy to reap the benefits of diversification

The two polar cases of projects that are perfectly correlated and independent projects are described next. 


\section{B. Perfectly correlated projects}

We retain the assumption that project outcomes are perfectly correlated. Let $I$ denote the depositors' supply of funds to banks, which in turn lend these funds to firms. Since every firm is paired with a monitoring (intermediary) agent, the per-capita amount of internal funding of entrepreneurs is $k / 2$, since half of entrepreneurs' resources are spent in monitoring.

Thus, if an entrepreneur is a firm, he chooses $p$ to maximize

$$
p\left[\left(X-R^{L}\right) I+\frac{X k}{2}\right]-\frac{\alpha p^{2}}{2}
$$

The optimal choice of $p$ satisfies

$$
p^{*}=\frac{\left(X-R^{L}\right) I+\frac{X k}{2}}{\alpha}
$$

and its profits are given by

$$
\Pi^{E} \equiv p^{*} \frac{\left[\left(X-R^{L}\right) I+\frac{X k}{2}\right]}{2}
$$

If the entrepreneur is a bank, its profits are:

$$
\Pi^{B} \equiv p^{*}\left(R^{L}-R^{D}\right) I
$$

In equilibrium, the level of $R^{L}$ determines entrepreneurs' specialization choices. If $R^{L}$ is such that $\Pi^{E}>\Pi^{B}$, then all entrepreneurs would prefer to be firms, but they would not obtain any financing. Conversely, if $R^{L}$ is such that $\Pi^{E}<\Pi^{B}$, all entrepreneurs would prefer to be banks, but there would be no firm they could lend to. Therefore, a necessary condition for an equilibrium with both firms and banks to exist is that an entrepreneur is indifferent 
between being a firm or a bank. This occurs for the equilibrium value of $R^{L}$ that satisfies $\Pi^{E}=\Pi^{B}$, which is given by:

$$
R^{L}=\frac{X}{3}\left(1+\frac{k}{2 I}\right)+\frac{2}{3} R^{D}
$$

Equation (31) shows that $R^{L}$ is a positive function of $R^{D}$, as a higher cost of funding for the bank is partially passed through raising the lending rate charged to firms. On the other hand, a larger $I$ translates into a lower lending rate, which, by Equation (28), induces firms to take on less risk ceteris paribus. This is the partial equilibrium $\mathrm{CVH}$ effect leading risk to decline with the total amount of loans obtained by Boyd and De Nicolò (2005).

Finally, substituting (31) in (28) and (29), one obtains expressions for risk and entrepreneurs profits given by:

$$
\begin{gathered}
p^{*}=\frac{\frac{2}{3}\left(X-R^{D}\right) I+\frac{X k 5}{6}}{\alpha} \\
\Pi^{E}(I)=\frac{\left[\frac{2}{3}\left(X-R^{D}\right) I+\frac{X k 5}{6}\right]^{2}}{2 \alpha}
\end{gathered}
$$

When we set $R^{D}=R,(32)$ and (33) yield the same type of expressions of equations (8) and (9), which are the equilibrium conditions determining the level of risk and the partition of agents between entrepreneurs and depositors for the economy with intermediaries and depositors only . Equation (10), the third equilibrium condition in that economy, remains unchanged in this extension of the model. Hence, all derivations and propositions applied to the moral hazard economy with banks and depositors apply to this moral hazard economy with firms, banks and depositors. 


\section{Independent Projects}

Here we assume that project outcomes are independent. Thus, given a choice of $p$, for any positive measure of firms, $p$ is also the fraction of successful firms, that is, firms whose realization of the project outcome is $X$. In this case, intermediation is necessary in allowing the economy to reap the benefits of diversification, for a setting with imperfect diversification see Krasa and Villamil (1992). Without banks' monitoring of the outcomes of individual projects, it would not feasible to assess the true fraction of successful projects, and thus construct a perfectly diversified loan portfolio.

Following the same line of arguments used previously, note that if an entrepreneur is a firm, he chooses $p$ to maximize

$$
p X\left(I+\frac{k}{2}\right)-R^{L} I-\frac{\alpha p^{2}}{2}
$$

The optimal choice of $p$ satisfies

$$
p^{*}=\frac{X\left(I+\frac{k}{2}\right)}{\alpha}
$$

and its profits are :

$$
\Pi^{E} \equiv \frac{X^{2}\left(I+\frac{k}{2}\right)^{2}}{2 \alpha}-R^{L} I
$$

If an entrepreneur is a bank, then its profits are:

$$
\Pi^{B} \equiv\left(R^{L}-R^{D}\right) I
$$

An entrepreneur is indifferent between being a firm and a bank when the value of $R^{L}$ satisfies $\Pi^{E}=\Pi^{B}$. Such value is given by: 


$$
R^{L}=\frac{X^{2}\left(I+\frac{k}{2}\right)^{2}}{4 \alpha I}+\frac{1}{2} R^{D}
$$

Substituting (38) in (36), one obtains:

$$
\Pi^{E}(I)=\frac{X^{2}\left(I+\frac{k}{2}\right)^{2}}{4 \alpha}-\frac{I}{2} R^{D}(39)
$$

Similarly to the previous case, when we set $R^{D}=R$, (35) and (39) yield the same type of expressions of equations (15) and (16), which are the equilibrium conditions determining the level of risk and the partition of agents between entrepreneurs and depositors for the economy with intermediaries and depositors only and no-moral hazard. Equation (17), the third equilibrium condition in that economy, remains unchanged in this extension of the model. Hence, all derivations and propositions applied to the no-moral hazard economy with banks and depositors apply to this moral hazard economy and independent risks with firms, banks and depositors.

\section{Conclusion}

We studied versions of a simple general equilibrium model in which intermediation is essential, agents make their investment and financing decisions under moral hazard and the CVH applies. We showed that more competition, in the form of lower banks' market power rents, results in lower economy-wide risk, lower bank capitalization, more efficient production plans and Pareto-ranked real allocations. Perfect competition, defined as the absence of market power rents, supports a best allocation, as well as optimal levels of risk and bank capitalization in several variations of our model. 
Thus, a general equilibrium economy which embeds investment choices subject to moral hazard of the type modeled by a large partial equilibrium literature, delivers implications entirely opposite to what these partial equilibrium constructs would predict. In essence, the partial equilibrium implications of the $\mathrm{CVH}$ do not necessarily hold in general equilibrium. If any inefficiency or financial instability arising from "excessive" competition indeed exists, then it should be identified and modeled in a general equilibrium set-up. As noted, however, a number of recent empirical studies support our theoretical results.

Conclusions derived from partial equilibrium modeling that are not robust to general equilibrium extensions are likely to result in unwarranted welfare implications. Developing general equilibrium set ups in which the nexus between bank capital and risk is defined not only relative to individual institutions, but at a system level, appears of great relevance in understanding the implications of systemic risk for the design of optimal capital regulations.

A general equilibrium perspective of bank regulation has been scarcely explored theoretically, and has so far been absent in policy discourse. But the current financial crisis provides a stark example of the dichotomy between a partial and a general equilibrium view of the world and its real consequences. Serious difficulties have arisen in financial institutions well adhering to minimum capital requirements designed—in a partial equilibrium perspective - to control individual banks' risk taking incentives. General equilibrium modeling of intermediation appear an essential tools to throw light on the desirable level of systemic risk in the economy, and how it could be attained. We aim at contributing to this research agenda in the future. 


\section{APPENDIX}

Proposition 1. In the moral hazard economy with banks and depositors an equilibrium with intermediation exists and it is unique for every $R \in\left(\frac{X k}{2 W}, X\right]$.

Proof: Rearranging (9) and rewriting (10), we obtain:

$$
\begin{gathered}
I_{1}(q) \equiv I=\frac{2 R W q-X k}{X-R}(\mathrm{~A} 1) ; \text { and } \\
I_{2}(q) \equiv I=\frac{W}{2}\left(1-q^{2}\right)(\mathrm{A} 2) .
\end{gathered}
$$

An equilibrium is a value of $q \in(0,1)$ that satisfies (A1) and (A2). Observe that $I_{2}(0)=\frac{W}{2}>-\frac{X k}{X-R}=I_{1}(0)$, while $I_{2}(1)=0<\frac{2 R W-X k}{X-R}=I_{1}(1)$ if $R \geq \frac{X k}{2 W}$, which is necessary for $I_{1}$ to be non-negative for every value of $q \in(0,1)$, otherwise no equilibrium 
would exist. Let $F(q) \equiv I_{2}(q)-I_{1}(q)=\frac{W}{2}\left(1-q^{2}\right)-\frac{2 R W q-X k}{X-R}$. Clearly, $F^{\prime}(q)<0$ holds.

Therefore, there exists a unique value of $q^{*} \in(0,1)$ such that $F\left(q^{*}\right)=0 . I^{*}$ is found using either (A1) or (A2). Using (8), $p^{*}=\alpha^{-1}\left[(X-R) I^{*}+X k\right]$. Q.E.D.

Proposition 2. In the moral hazard economy with banks and depositors:

$$
I_{R}^{*}>0, \hat{q}_{R}^{*}<0, p_{R}^{*}>0, K_{R}^{*}<0 \text { and } p_{k}^{*}>0 .
$$

Proof: Differentiating totally (9) and (10) with respect to $I, q, R$ and $k$, we get:

$$
\begin{gathered}
\frac{X-R}{2} d I-R W d q=q W d R-\frac{X}{2} d k \\
d I+q W d q=0
\end{gathered}
$$

The determinant of the system (A3)-(A4) is $\Delta=\frac{X-R}{2} q W+R W>0$.

Setting $d k=0$, by Cramer's rule,

$$
I_{R}=\frac{d I}{d R}=\frac{1}{\Delta}(q W)^{2}>0
$$

and

$$
q_{R} \equiv \frac{d q}{d R}=-\frac{1}{\Delta} q W<0 \quad(\mathrm{~A} 6) .
$$

Substituting (A1) in (8), we get:

$$
p=\frac{2 R W q}{\alpha}
$$

Differentiating (A7) with respect to $R$, we get: 


$$
p_{R} \equiv \frac{d p}{d R}=\frac{2 W q}{\alpha}+\frac{2 R W}{\alpha} q_{R}=\frac{2 W q}{\alpha}\left(1-\frac{R W}{\Delta}\right)>0
$$

where the second equality was obtained using (A6), and the last inequality derives from $\Delta>R W$.

Finally, by (A5) and (A6)

$$
K_{R}=\frac{k}{(I+q k)^{2}}\left(q_{R} I-q I_{R}\right)<0
$$

Setting $d R=0$ and following the same procedure above, we obtain:

$$
q_{k} \equiv \frac{d q}{d k}=\frac{X}{2 \Delta}>0 \quad(\mathrm{~A} 10)
$$

Therefore,

$$
p_{k} \equiv \frac{d p}{d k}=\frac{2 R W}{\alpha} q_{k}>0
$$

Q.E.D.

Proposition 3. , In the no-moral hazard economy with banks and depositors an equilibrium with intermediation exists and it is unique for every $R \in\left(\frac{X^{2} k^{2}}{2 \alpha W}, \frac{X^{2}(W+2 k)^{2}}{4 \alpha W}\right)$.

Proof: Rearranging (16) and (17), we obtain:

$$
\begin{gathered}
q_{1}(I) \equiv q=\frac{X^{2}(I+k)^{2}}{2 \alpha R W}-\frac{I}{W} \quad(\mathrm{~A} 9) ; \text { and } \\
\left.q_{2}(I) \equiv q=\sqrt{1-\frac{2 I}{W}} \quad \text { (A } 10\right) .
\end{gathered}
$$

An equilibrium is a value of $I \in\left(0, \frac{W}{2}\right]$ that satisfies (A1) and (A2). 
Observe that $q_{1}(0)=\frac{X^{2} k^{2}}{2 \alpha R W}, q_{1}(I)$ is strictly concave in $I$ and strictly decreasing for all $I>I_{\max }$, where $I>I_{\max }$ is the maximum of $q_{1}(I)$. Thus, there exists a value $\hat{I}>I_{\max }$ such that $q_{1}(\hat{I})=0$. On the other hand, $q_{2}(0)=1, q_{2}(I)$ is strictly decreasing, and $q_{2}\left(\frac{W}{2}\right)=0$.

Thus, a unique intersection of $q_{1}(I)$ and $q_{2}(I)$ - that is, a value of $I \in\left(0, \frac{W}{2}\right]$ that satisfies

(A1) and (A2)—will occur for some $I \in\left(0, \frac{W}{2}\right]$ only if $q_{2}(0)=1 \geq \frac{X^{2} k^{2}}{2 \alpha R W}=q_{1}(0)$ (A11), and $q_{2}\left(\frac{W}{2}\right)=0 \leq \frac{X^{2}(W+2 k)^{2}}{8 \alpha R W}-\frac{1}{2}=q_{1}\left(\frac{W}{2}\right)$ (A12). Inequality (A11) implies $R \geq \frac{X^{2} k^{2}}{2 \alpha W}$, while inequality (A12) implies $R \leq \frac{X^{2}(W+2 k)^{2}}{4 \alpha W}$. Thus, for every $R \in\left(\frac{X^{2} k^{2}}{2 \alpha W}, \frac{X^{2}(W+2 k)^{2}}{4 \alpha W}\right)$, an equilibrium exists and it is unique. Using (15), $p^{*}=\alpha^{-1}\left[X\left(I^{*}+k\right)\right]$.

Q.E.D.

Proposition 4. In the no-moral hazard economy with banks and depositors:

$$
I_{R}^{*}>0, \hat{q}_{R}^{*}<0, p_{R}^{*}>0, K_{R}^{*}<0 \text { and } p_{k}^{*}>0 .
$$

Proof: Differentiating totally (16) and (17) with respect to $I, q, R$ and $k$, we obtain:

$$
\begin{gathered}
\left(\frac{X^{2}(I+k)}{\alpha}-R\right) d I-R W d q=(q W+I) d R-\frac{X^{2}(I+k)}{\alpha} d k \\
d I+q W d q=0
\end{gathered}
$$

The determinant of the system (A13)-(A14) is $\Delta=\frac{X^{2}(I+k)}{\alpha} q W+R W(1-q)>0$.

Setting $d k=0$, by Cramer's rule, 


$$
\begin{gathered}
I_{R}=\frac{d I}{d R}=\frac{1}{\Delta}(q W+I) q W>0 \quad(\mathrm{~A} 15), \quad \text { and } \\
q_{R} \equiv \frac{d q}{d R}=-\frac{1}{\Delta}(q W+I)<0 \quad \text { (A16). }
\end{gathered}
$$

Differentiating (15) with respect to $R$, we get:

$$
p_{R} \equiv \frac{d p}{d R}=\frac{X I}{\alpha} I_{R}>0
$$

where we have used (A15).

Finally, by (A15) and (A16)

$$
K_{R}=\frac{k}{(I+q k)^{2}}\left(q_{R} I-q I_{R}\right)<0
$$

Setting $d R=0$, and following the same procedure above, we obtain:

$$
I_{k}=\frac{d I}{d k}=-\frac{1}{\Delta} q W \frac{X^{2}(I+k)}{\alpha}<0 \quad(\mathrm{~A} 20),
$$

Hence,

$$
p_{R} \equiv \frac{d p}{d R}=\frac{X}{\alpha}\left(I_{k}+1\right)=\frac{X}{\alpha}\left(1-\frac{q W X^{2}(I+k) \alpha^{-1}}{q W X^{2}(I+k) \alpha^{-1}+R W(1-q)}\right)>0,(\mathrm{~A} 21),
$$

where we have used (A20) and $\Delta$.

Q.E.D.

Proposition 5. In the moral hazard economy with banks and depositors, there is no equilibrium with intermediation that supports the Pareto optimal allocation.

Proof: Inserting (10) in (8), replacing $(p, q)$ with $\left(p^{o}, q^{o}\right)$ in (8) and (9), and solving for $R$ in (8) and (9) respectively, we obtain 


$$
\begin{aligned}
& R_{1} \equiv R=X+\frac{2 X k-2 \alpha p^{O}}{W\left(1-q^{\mathscr{D}}\right)} \\
& R_{2} \equiv R=\frac{X W\left(1-q^{\mathcal{D}}\right)+2 X k}{W\left(1-q^{\mathcal{D}}\right)+4 q^{O} W}
\end{aligned}
$$

Using (24) in (A22) and (A23) yields $R_{1}=0 \neq \frac{4 X W}{4 W-2 k+20 W \sqrt{\frac{2 k+W}{5 W}}}=R_{2}$.

Thus, there does not exist a value of which yields an equilibrium with $(p, q)=\left(p^{O}, q^{O}\right)$.

Thus, there is no equilibrium that supports the Pareto optimal allocation.

Q.E.D.

Proposition 6. In the moral hazard economy with banks and depositors, $R^{*}$ is an equilibrium with intermediation that supports the second best allocation.

Proof: A solution $R^{*}$ to problem (25) subject to (26) exists, since the continuous function $V($.$) in (25) is maximized over the compact set (26). Since function V($.$) is strictly concave$ in $(p, q)$, there exist a unique pair $\left(\hat{p}^{*}, \hat{q}^{*}\right)$ that solves (25) subject to (26). Since $\hat{p}(R)$ and $\hat{q}(R)$ are uniquely determined by the equilibrium conditions (8)-(10), there exists a unique $R^{*}$ such that $\hat{p}^{*}=\hat{p}\left(R^{*}\right)$ and $\hat{q}^{*}=\hat{q}\left(R^{*}\right)$.

Q.E.D.

Proposition 7. In the no-moral hazard economy with banks and depositors, there exist a unique $R^{0}$ such that the corresponding equilibrium with intermediation supports the (first best) Pareto optimal allocation.

Proof: Using (17) and $\left(p^{O}, q^{O}\right)$ in (15) and (16), we obtain:

$$
2 \alpha p^{O}=X\left(W\left(1-q^{D}\right)+2 k\right)(
$$




$$
X^{2}\left(\frac{W}{2}\left(1-q^{\mathscr{D}}\right)+k\right)^{2}-\alpha R W\left(1-q^{\mathcal{D}}\right)=2 \alpha R q^{O} W(\mathrm{~A} 25)
$$

Equation (A24) is independent of $R$. Solving (A25) for $R$, we obtain:

$$
R^{*}=\frac{\left(2 k+W\left(1-q^{D}\right)\right)^{2} X^{2}}{4 \alpha W\left(1+2 q^{O}-q^{D}\right)} .
$$

Lastly, we need to verify that $R^{*}$ is an equilibrium. By proposition 3 , this amounts to verify that $R^{*} \in\left(\frac{X^{2} k^{2}}{2 \alpha W}, \frac{X^{2}(W+2 k)^{2}}{4 \alpha W}\right)$. Thus, $R^{*}$ is an equilibrium if

$$
\frac{X^{2} k^{2}}{2 \alpha W}<\frac{\left(2 k+W\left(1-q^{D}\right)\right)^{2} X^{2}}{4 \alpha W\left(1+2 q^{O}-q^{D}\right)}(\mathrm{A} 27)
$$

and

$$
\frac{\left(2 k+W\left(1-q^{0}\right)\right)^{2} X^{2}}{4 \alpha W\left(1+2 q^{O}-q^{0}\right)}<\frac{X^{2}(W+2 k)^{2}}{4 \alpha W}(\mathrm{~A} 28) .
$$

Rearranging (A27), we obtain

$$
4 k^{2}+W^{2}\left(1-q^{D}\right)^{2}+4 k W\left(1-q^{D}\right)>2 k^{2}\left(1+2 q^{O}-q^{D}\right)(\mathrm{A} 29) .
$$

By assumption, $k<1, W>1$ and $0 \leq q \leq 1$. Therefore, $2 k^{2}\left(1+2 q^{O}-q^{D}\right) \leq 4 k^{2}$ and $W^{2}\left(1-q^{\circlearrowright}\right)^{2}+4 k W\left(1-q^{D}\right)>0$. Thus, inequality (A29) holds, hence, inequality (A27) is verified.

(A28) is equivalent to

$$
2 k+W\left(1-q^{\mathscr{D}}\right)<(2 k+W) \sqrt{1+2 q^{O}-q^{\oslash}}(\mathrm{A} 30)
$$

Since $1 \leq 1+2 q^{O}-q^{D} \leq 2$ and $1-q^{D} \leq 1$, (A30) holds, thus (A28) is verified. Q.E.D. 
Proposition 8 In both the moral-hazard and no-moral hazard economies with banks and depositors, the equilibrium level of risk $\hat{p}$ converges to the optimal level of risk $p^{*}$ from below, to the optimal level of bank capitalization $K^{*}$ from above, and to a best allocation as market power rents vanish, i.e. $\hat{p} \uparrow p^{*}$, and $\hat{K} \downarrow K^{*}$ as $\rho \rightarrow 0$.

Proof: By propositions 2 and 4, $\hat{p}$ increases monotonically in $R$. By propositions 6 and 7 , there exists a unique optimal $R^{*}$ that supports the optimal level of risk $p^{*}$. Therefore $\hat{p}(R) \uparrow \hat{p}\left(R^{*}\right)=p^{*}$ and $\hat{K}(R) \downarrow \hat{K}\left(R^{*}\right)=K^{*}$ as $\rho=R^{*}-R \rightarrow 0$ Q.E.D.

\section{REFERENCES}

Allen, Franklin, and Douglas Gale, 2000, “Comparing Financial Systems” (MIT Press, Cambridge, Massachusetts)

Allen, Franklin, and Douglas Gale, 2004a, "Competition and Financial Stability”, Journal of Money, Credit and Banking 36(2), 453-480.

Allen, Franklin, and Douglas Gale, 2004b, "Financial Intermediaries and Markets", Econometrica, Vol. 72, 4, 1023-1061. 
Akins, B., Li, L., Ng, J., and Rusticus, T. O. 2016. "Bank Competition and Financial Stability: Evidence from the Financial Crisis", Journal of Financial and Quantitative Analysis, 51(01), 1-28.

Barth, J.R., Caprio, Jr., G., and Levine, R., 2004, "Bank supervision and Regulation: What Works Best?', Journal of Financial Intermediation 13:2, 205-48.

Beck, T., Demirgüç-Kunt, A., and Levine, R., 2006a, "Bank concentration, competition, and crises: First results” Journal of Banking and Finance 30, 1581-603.

Beck, T., Demirgüç-Kunt, A., and Levine, R., 2006b, "Bank concentration and fragility: Impact and mechanics' In: Stulz, R., and Carey, M. (eds), The Risks of Financial Institutions. National Bureau of Economic Research.

Berger, Allen N., Leora F. Klapper, and Rima Turk-Ariss. 2009, “Bank Competition and Financial Stability.” Journal of Financial Services Research 35, 2, 99-118.

Booth, Arnoud W., and Thakor, Anjan V., 1997, "Financial System Architecture” The Review of Financial Studies, Vol. 10, 3, 693-733.

Boyd, John H., Chung, Chang, and Bruce, D. Smith, 2002, “Deposit Insurance: A reconsideration” Journal of Monetary Economics,49, 1235-1260.

Boyd, John H., and Gianni De Nicolò, 2005, “The Theory of Bank Risk Taking and Competition Revisited”, Journal of Finance, Volume 60, Issue 3, 1329-1343.

Boyd, John H., Gianni De Nicolò and Abu M. Jalal, 2006, “Bank Risk and Competition: New Theory and New Evidence”, IMF Working Paper \# 06/297, International Monetary Fund, Washington D.C. 
Boyd, John H., Gianni De Nicolò and Abu M. Jalal, 2009, "Bank Competition, Risk, and Asset Allocations”, IMF Working Paper 09/143, International Monetary Fund, Washington D.C.

Boyd, John H., Gianni De Nicolò and Bruce D. Smith, 2004, "Crises in Competitive versus Monopolistic Banking Systems”, Journal of Money Credit and Banking 36, 3, 487506.

Boyd, John H , Gianni De Nicolò and Elena Loukoianova, 2008, "Banking Crises and Crisis Dating: Theory and Evidence", IMF Working Paper 09/141, International Monetary Fund, Washington D.C.

Boyd, John H. and Edward Prescott, 1986, "Financial Intermediary Coalitions", Journal of Economic Theory, 38, 211-232.

Cetorelli Nicola, and Gambera Michele, 2001, "Banking Market Structure, Financial Dependence and Growth: International Evidence from Industry Data", Journal of Finance, 56(2), 617-648.

Cetorelli Nicola, and Philip Strahan, 2006, "Finance as a Barrier to Entry: Bank Competition and Industry Structure in Local U.S. Markets", The Journal of Finance 61(1), 437661.

Cordella Tito, and Levi-Yeyati, 2002, "Financial Opening, Deposit Insurance, and Risk in a Model of Banking Competition", European Economic Review 46, 693-733.

De Nicolò, Gianni and Elena Loukoianova, 2007, "Bank Ownership, Market Structure and Risk”, IMF Working Paper, 07/215, International Monetary Fund, Washington D.C. De Nicolò, Gianni and Rima Turk Ariss, 2009, "Bank Market power Rents and Risk: Theory and Measurement", manuscript and forthcoming IMF Working Paper. 
Diamond, Douglas, 1984, "Financial Intermediation and Delegated Monitoring”, Review of Economic Studies, 51, 393-414.

Diamond, Douglas, and Philip Dybvig, 1983, "Bank Runs, Liquidity and Deposit Insurance”, Journal of political Economy, 91, 401-419.

Freixas, Xavier, and Jean-Charles Rochet, 2008, Microeconomics of Banking, ( MIT Press, Cambridge, Massachusetts).

Freixas, Xavier, and Ma, Kebin, 2015, "Banking Competition and Stability: The Role of Leverage", Barcelona GSE W.P. n. 781.

Gorton, Gary, and Andrew Winton, 2003, "Financial Intermediation”, Chapter 8 in Handbook of the Economics of Finance, edited by G.M.Constantinides, M. Harris and R., Stulz, Helsevier (Amsterdam).

Hellmann, Thomas, Kevin Murdock and Joseph Stiglitz, 2000, "Liberalization, moral hazard in banking, and prudential regulation: Are capital requirements enough?" American Economic Review 90(1), 147-165.

Holmstrom, Bengt, and Tirole, Jean, August 1997, "Financial Intermediation, Loanable Funds, and the Real Sector" The Quarterly Journal of Economics CXII 3, 663-691.

Jayaratne J., and Strahan P., 1998, “Entry Restrictions, Industry Evolution, and Dynamic Efficiency: Evidence From Commercial Banking', Journal of Law and Economics 41, 239-275.

Krasa, S. and A. Villamil, 1992, “A Theory of Optimal Bank Size,” Oxford Economic Papers,

44, 1992, 38-63 
Keeley, Michael, 1990, “Deposit Insurance, Risk and Market Power in Banking”, American Economic Review 80, 1183-1200.

Matutes, Carmen, and Vives, Xavier,1996, “Competition for Deposits, Fragility, and Insurance", Journal of Financial Intermediation 5, 186-216.

Martinez-Miera, David, and Repullo, Raphael, 2010, “Does Competition Reduce the Risk of Bank Failure?", Review of Financial Studies, 23, 10, 3638-3664.

Maudos, Joaquin, and Juan Fernandez de Guevara, 2007, “The cost of market power in banking: Social welfare loss vs. cost inefficiency", Journal of Banking \& Finance $31.7,2103-2125$.

Repullo, Raphael, 2004, “Capital Requirements, Market Power, and Risk-Taking in Banking”, Journal of Financial Intermediation, Vol. 13, 156-182.

Zigraiova, Diana, and Havranek, Tomas, 2015, "Bank Competition and Financial Stability: Much Ado about Nothing", Journal of Economic Surveys. 